\title{
CULTURAL LANDSCAPES SPACE-TEMPORAL SYSTEMATIZATION OF INFORMATION IN GEOPORTALS FOR THE PURPOSES OF REGION TOURIST AND RECREATIONAL DEVELOPMENT
}

\author{
Anatoliy A. YAMASHKIN \\ National Research Ogarev Mordovia State University, Faculty of Geography, \\ 68 Bolshevistskaya St., Saransk 430005, Russia, e-mail: yamashkin56@mail.ru
}

\section{Stanislav A. YAMASHKIN*}

National Research Ogarev Mordovia State University, Institute Of Electronics And Lighting Engineering, 68 Bolshevistskaya St., Saransk 430005, Russia, e-mail: yamashkinsa@mail.ru

\section{Marina Yu. AKSYONOVA}

Ulyanovsk State Pedagogical University named after I.N. Ulyanov, Natural-Geographical Faculty, 4/5 Lenin Square, Ulyanovsk 432071, Russia, e-mail: 82axmarina@mail.ru

\section{Marija CIMBALJEVIĆ}

University of Novi Sad, Faculty of Sciences, Department of Geography, Tourism and Hotel Management 1 Dr Zorana Đinđića, Novi Sad 21102, Republic of Serbia, e-mail: marija.cimbaljevic@dgt.uns.ac.rs

\section{Dunja DEMIROVIĆ}

Geographical Institute "Jovan Cvijici" SASA, 9 Djure Jakšića, Belgrade 110oo, Republic of Serbia, e-mail: d.demirovic@gi.sanu.ac.rs

\section{Nikola VUKSANOVIĆ}

Higher Education School for Management and Business Communication, Department ofHospitality, 110 Mitropolita Stratimirovića Street, Sremski Karlovci 21205, Republic of Serbia, e-mail: vuksanovicnikola85@gmail.com

\section{Nikola MILENTIJEVIĆ}

University of Priština, Faculty of Sciences and Mathematics, Department of Geography, Filipa Višnjiča bb, Kosovska Mitrovica 38220, Republic of Serbia, e-mail: nikola.milentijevic@pr.ac.rs

Citation: Yamashkin, A.A., Yamashkin, S.A., Aksyonova, M.Yu., Cimbaljević, M., Demirović, D., Vuksanović, N., \& Milentijević, N. (2020). CULTURAL LANDSCAPES SPACE-TEMPORAL SYSTEMATIZATION OF INFORMATION IN GEOPORTALS FOR THE PURPOSES OF REGION TOURIST AND RECREATIONAL DEVELOPMENT. GeoJournal of Tourism and Geosites, 29(2), 440-449. https://doi.org/10.30892/gtg.29205-480

\begin{abstract}
The manuscript is devoted to the study of the scientific problem of space-temporal systematization of information on cultural landscapes in geoportals and spatial data infrastructures for the purpose of tourist and recreational development of the region. The paper emphasizes that the processes of integration, refinement and structuring of information on the spatio-temporal organization of
\end{abstract}

\footnotetext{
* Corresponding author
} 
Cultural Landscapes Space-Temporal Systematization of Information

in Geoportals for the Purposes of Region Tourist and Recreational Development

cultural landscapes can be optimized with the coordinated development of a regional problem-oriented GIS, a remote sensing data processing and analysis system, and a web-based geoportal. The authors give an example of the visualization of information resources about cultural landscapes through the development of the geoportal "Natural and Cultural Heritage of Mordovia", available at tourismportal.net. The functioning of the project is based on the provision that the process of researching national landscapes should be based on a spatio-temporal systematization and comparative analysis of large volumes of information in order to form an idea of the harmonization of the interaction of nature and society at different hierarchical levels of ethno-geographical space.

Key words: cultural landscapes, space-temporal systematization, geoportals, tourism, recreational development, GIS technologies

\section{PROBLEM STATEMENT}

The patterns of the origin and development of ecological-socio-economic systems of ethno-cultural space depend on the nature of the territories inborn landscapes, the features of population life support systems evolution and the nature of ethnic groups development that determine together the formation of material and spiritual heritage. These patterns are manifested in the change and possible coexistence of different types of cultural landscapes that should be considered as a kind of society reflection that transform it during a long time. This thesis is very figuratively disclosed by V.A. Nikolaev (Nikolaev, 2000), he writes: “A pattern has been established: what is society, its culture, mentality and historical fate, so will the landscape created by it”. He further notes: "The national cultural landscape is the "race" of generations".

Cultural landscapes and the objects of natural and historical heritage contained in them form a qualitatively new level of its spatiotemporal organization as a tourist destination (Wang \& Fesenmaier, 2008; Gordon, 2018) - a combination of natural, social and economic preconditions for the recreation and tourism development. A unique component of the cultural landscape is the sacred system - the result of the intellectual and spiritual activity of people in creating its shape (Swetnam, 2017).

Its structure is formed by the pragmatic economic and informational development of the territory, revealed in the natural and cultural heritage, semantics and symbols (Taylor, 2008; Van Der Valk, 2014). The main function of sacred landscapes is social integration that implemented in the creation of a "collective imaginary" (Okladnikova, 2014). In general, sacred landscapes are space-temporal formations that multi-variously reflect the processes of landscapes economic development. In addition, sacred loci are "national images of the world" of various peoples, the main purpose of which is to transfer socially significant cultural traditions from the past to the future. Thus, the concepts "cultural landscape" and "sacred landscape" in modern science are considered as a multifunctional phenomenon, its essence in the transmission of social experience in adapting to a specific natural landscape from generation to generation. An urgent task is the space-temporal natural and historical heritage systematization and the formation of information resources (Katsoni, 2015). On their basis, a planned and consistent work of the governing bodies on its use for the sustainable tourism and recreation development should be deployed. 
Anatoliy A. YAMASHKIN, Stanislav A. YAMASHKIN, Marina Yu. AKSYONOVA, Marija CIMBALJEVIĆ, Dunja DEMIROVIĆ, Nikola VUKSANOVIĆ, Nikola MILENTIJEVIĆ

\section{MATERIALS AND RESEARCH METHODS}

Work with heterogeneous data, revealing the features of the co-creation of society and nature in time, should have a powerful information basis (Tieskens, 2018; Taylor, 2012). This will ensure the collection, storage, analysis, visualization and dissemination of information about the spatiotemporal structure of ethno-geographical space. Structuring and visualization of ethno-geographical space can be represented in three dimensions. Space should be considered in vertical and horizontal (territorial) aspects. In the vertical structure of the cultural landscape in web-based geographical information systems (GIS) visualizations are subject to:

- natural subsystem - lithogenic base, climate, surface and underground waters, soils, vegetation and wildlife, landscapes;

- social subsystem - resettlement system, ethnic, gender and age structure, systems of artifacts (elements characterizing the connection of a people community with the material environment - tools, housing, clothing, etc.), mental factors (persistent sociopsychological elements of culture - religion, language, music, dance, aesthetic ideals, etc.), social facts (elements that determine sustainable social ties between people - institutions of family, education, etiquette, etc.);

- manufacturing subsystem - industrial and agricultural production facilities, transport and logistics complexes, non-production services.

In the vertical structure of cultural landscapes, a certain type of interaction of natural, social and industrial subsystems is formed. It includes the natural landscape, which regulates the environment and reproducing resources processes in the natural environment surrounding society and especially valuable natural areas; prevailing settlement systems with water and land routes for economic development of the territory, which determined the features of settlement in the region; traditional and modern production potential with places for the crafts development; land use types adapted to the structure of the natural framework, taking into account the natural potential and sustainability of natural complexes; ethnographic peculiarity of the area, taking into account the material and spiritual culture of ethnic groups; monuments of archeology, history and culture, which are in functional and spatial connection with the landscape environment; landscape images and symbols that formed as a result of the organic interaction of nature and multifaceted human activity; the mythological layer, revealed by a multitude of mythological characters that came into it from fairy tales, beliefs, memories, and literature; cultural traditions that regulate human relations with the environment; toponymy that is structuring the space in individual consciousness; innovative elements that reflect the implantation of qualitatively new objects, technologies, and traditions into the modern cultural landscape (Schulp, 2019).

Collectively, the cultural landscape determines the historical, artistic, scientific and cognitive value of the region. Systems of related cultural landscapes determine the horizontal (territorial) structure of the ethno-cultural space. The most difficult issue of its visualization in cartographic geographic information models is the determination of the boundaries of territorial complexes. Possessing considerable continuity, the boundaries of the ethno-geographical space are drawn taking into account a number of factors: natural, ethno-cultural, political and administrative, etc.

Borders between territorial formations perform complementary functions: on the one hand, the relative isolation of homogeneous cultural or sacred landscapes, on the other hand, to ensure continuous communication and contact between them. Study of the temporal structure of cultural landscapes has a particular importance. It should be carried out taking into account the successive change in the types of economic and 
cultural interaction with the natural landscape at the level of intervals of different durations: stages, periods and phases. In chronological approach, as in the visualization of the territorial structure, the leading factor that determines the type of interaction between nature and society is a man himself. So, K.P. Kosmachev writes: “... the active side that determines the type of development of a territory always a society is. But the result of development largely depends on the territory natural basis, and how it "takes" the impact of society, how it is able to accumulate the results of human labor and preserve them for a long time" (Kosmachev, 1974, p. 98). As part of the visualization of ethno-geographical space, special attention is paid to the analysis of the host natural landscape. The later determines the structure of the socio-economic organization of the territory, the development of material and spiritual culture, the analysis of the degree of development of conflict situations and the problems of preserving the cultural landscape natural and historical heritage over a certain time period.

The development of cultural landscapes is metachronous in its nature, and as a result of this phenomenon, there is a peculiar manifestation of interaction between the nature and society in different time "sections" and the close interweaving of different layers of natural and historical heritage in specific regions. Interconnections between natural and historical heritage sites are ensured through their intercommunion. The disclosure of communication-positions and relationship-interactions between components in the structure of the cultural landscape has the following features:

- firstly, communication-positions in cultural and especially in sacred landscapes do not always have physical meaning, which is conceptualized in the form of material and spiritual heritage that determines land use systems, forms of nature management, geoecological problems, etc.;

- secondly, the various tightness of the communication-positions and relationshipinteractions between the elements of the cultural landscape allows us to talk about their functional purpose, and the possibility of optimizing the interaction of residential, agricultural, forestry, industrial, transport, hydraulic, mining, and recreational systems;

- thirdly, the social subsystem of cultural landscapes tends, as a rule, to reduce the entropy of the entire system, that is, to increase the ordering of elements and relationship-interactions between natural and industrial subsystems;

- fourthly, the cultural landscape in its space-temporal structure, the focal points of which are sacred complexes, accumulates the interconnections between natural, social and manufacturing subsystems, providing an information basis for their visualization.

GIS technologies in the cultural landscapes structure modeling for tourist regions and recreation development. Modern trends in the development of geographical science as an information base for studying the cultural landscapes natural and historical heritage determine uniquely the geographical information systems (GIS), to provide the entire technological chain of work with information: collection, storage, analysis, synthesis, visualization, interpretation and distribution of information to potential consumers of Web. It is based on vector graphics and the widest possible use of raster data - Earth remote sensing (ERS) materials, which together represent a visual and semantic model of a complexly organized ethnographic space. Obviously, the elaboration of these models, the general and particular identification in structure of the cultural landscape at the local, regional and global levels is an interdisciplinary task that is based on the application of the theory, methodology and methods of geography, cartography and geo-informatics, cultural studies, as well as a number of other sciences.

The information base of a web-based GIS project for the analysis and assessment of regional natural and historical heritage is formed on the basis of information from 
Anatoliy A. YAMASHKIN, Stanislav A. YAMASHKIN, Marina Yu. AKSYONOVA, Marija CIMBALJEVIĆ, Dunja DEMIROVIĆ, Nikola VUKSANOVIĆ, Nikola MILENTIJEVIĆ

the natural and social sciences: historical, archaeological, ethnographic and toponymy, as well as on a complex of geographical data. The evaluation of natural heritage involves a comprehensive information analysis on the diversity of natural conditions and resources necessary for the life of the population and the functioning of economic objects (minerals, water, soil, plants and other resources).

Significant protected natural areas (nature reserves, national parks, natural monuments) are important components of the natural heritage. Assessment of historical heritage is based on information that characterize the territory stages of economic and information development (we mean nature management differentiation, settlement types, population size and ethnicity, etc.). Historical monuments (cultural layers, ancient cities buildings remains, pre-historic and ancient settlements; landscape architecture works and landscape gardening art; places of interest, centers of historical settlements or fragments of urban planning and development; memorials related to the prominent historical figures, etc.) are of particular importance (Smith, 2014; Brown, 2012). Structuring the ethno-geographic space receives logical development in solving problems of visualizing its model in web-based GIS projects which are desined to provide communication in the "man - cultural landscape" system.

The central task of analyzing the cultural landscape for recreation and tourism we see in the expanded disclosure of information about the tourist and recreational potential, in destination as an emergent phenomenon based on close relationships and interactions in space and time of natural, social and production subsystems.

At the present stage of development of public relations, the organization of tourist and recreational activities makes high demands on information support. It is determined by the high diversity of global and regional tourist markets and, therefore, by high potential differentiation of tourist flows. That is why the information factor plays an important role in its formation (Leiper, 1979). In the context of globalization, informatization, and the development of Internet technologies, prompt access to reliable spatially distributed information is crucial for all parties that participate in the tourism industry (Goeldner \& Ritchie, 2009): consumers (tourists, sightseers), subjects of tourism, governmental bodies etc. Any tourist information portal uses geographic atlases, interactive electronic maps, accumulating information on the features of the natural potential of the territory, cultural features, display facilities, tourist infrastructure, routes, etc. as an auxiliary tool for visualizing objects of ethno-geographical space.

When developing a geoportal based on spatial data infrastructure, an important task is the competent organization and visualization of geographical information. It promotes the high efficiency of interaction between the web-resource and the consumer (Gkonos et al., 2018). This problem must be solved both from the standpoint of webdesign and Earth sciences. The analysis of modern geoportals shows: despite the differences in topics, coverage of space and degree of development, decisions on the optimal visual representation of the space-temporal organization of the cultural landscape have common trends (Vîlceanu, 2017).

The organization of a geoportal as a web-resource is designed to provide the user with a convenient perception of virtual information. The cartographic information as the basis of any web-based GIS project is characterized by the model properties of virtual geo-images: software controllability (interactivity); thematic diversity (variation of combinations, sequence of electronic layers of geoportal maps); updatability (operational insertion of a new or editing of an existing information); multi-scale and multi-level organization (transformation of the detail of visual solutions in course of scaling); multimedia and high information content (two- and three-dimensional 
visualization formats, complementing traditional cartographic image methods with photographs, $360^{\circ}$ panoramas, profiles, graphs, video and sound materials that reveal the space-temporal features of ethno-geographical space images).

Further implantation of cartographic web-resources into the practice of managerial activity involves the development of space-temporal visualization technologies for cultural landscapes: the development of dynamic symbolic systems for displaying natural and historical heritage objects, semiotic principles of virtual modeling, and associative geoportal solutions as models of cultural landscapes (Koszewski et al., 2018). The paradigm associated with the use of objects of material and cultural heritage of landscapes in the economy will be useless if a critical analysis of the ecological-socio-economic reality that determines territorial ordering is not made (Whelan, 2016). The latter is a fundamental element in the sustainable development planning process. To solve the problem of sustainability, special tools are needed that can provide transparent relevant information related to the availability of local resources; various technological options are needed to optimally use them to meet the growing needs of society and timely assess the potential of resources.

All this requires a clear understanding in making decisions: from physical to functional, from administrative to economic that are aimed at sustainable development. The environmental impact of technology must also be considered.

\section{DISCUSSION}

The experience of studying the space-temporal cultural landscapes organization shows that the accumulation, refinement and structuring of information is optimized in the coordinated development of a regional problem-oriented GIS, a remote sensing data processing and analysis system, and a web-based GIS project. The basis of information support for the study of cultural landscapes of the Republic of Mordovia is the regional GIS "Mordovia". The creation of its databases was the result of solving the problems of harmonizing the interaction of natural, social and industrial systems of cultural landscapes: preparing territorial planning documents, ecological substantiation of urban planning documentation, designing specially protected natural territories, environmental engineering surveys, etc. Currently, the regional GIS includes electronic map and database systems that disclose information on natural conditions and resources, socio-economic development, ecology, natural and historical heritage sites.

The GIS complex allows conducting rapidly a comparative analysis of geoinformation in space and time, visualizing the structure of the cultural landscape to solve multidirectional applied problems. The GIS nodal link is an electronic synthetic landscape map. This map is both the result of branch research and the basic element of applied research to study the structure of the region cultural landscape (Yamash kin et al., 2003). One of the main sources of operational and reliable information for updating an electronic landscape map is a system for processing and analyzing remote sensing data of ERS. To solve the problems of assessing the state of natural, social and production systems, methods have been implemented for identifying localities in modeling the landscapes boundaries, analyzing spectral characteristics to determine the morphological landscape structure and modeling landscape diversity, neural networks and hybrid systems (Yamashkin et al., 2018) for the purpose of synthetic landscape mapping.

Visualization of information resources about cultural landscapes is carried out through the development of the geoportal "Natural and Cultural Heritage of Mordovia". It is available at https://tourismportal.net/. Visualization proceeds from the fact that the process of researching national landscapes should be based on space-temporal 
Anatoliy A. YAMASHKIN, Stanislav A. YAMASHKIN, Marina Yu. AKSYONOVA, Marija CIMBALJEVIĆ, Dunja DEMIROVIĆ, Nikola VUKSANOVIĆ, Nikola MILENTIJEVIĆ

systematization and comparative analysis of large volumes of information in order to form an idea of the harmonization of nature and society interaction at different hierarchical levels of ethno-geographical space (Yamashkin et al., 2019). For the technical implementation of project modern engineering solutions were used. That allows providing the high efficiency in the collection, storage, processing and provision of relevant geospatial information about the national cultural and natural landscape of Mordovia: optimized interface solutions, adaptive design, relational geospatial data warehouses, and a modular multi-component software framework. From the software implementation resource, the system is based on the Model-View-Controller pattern.

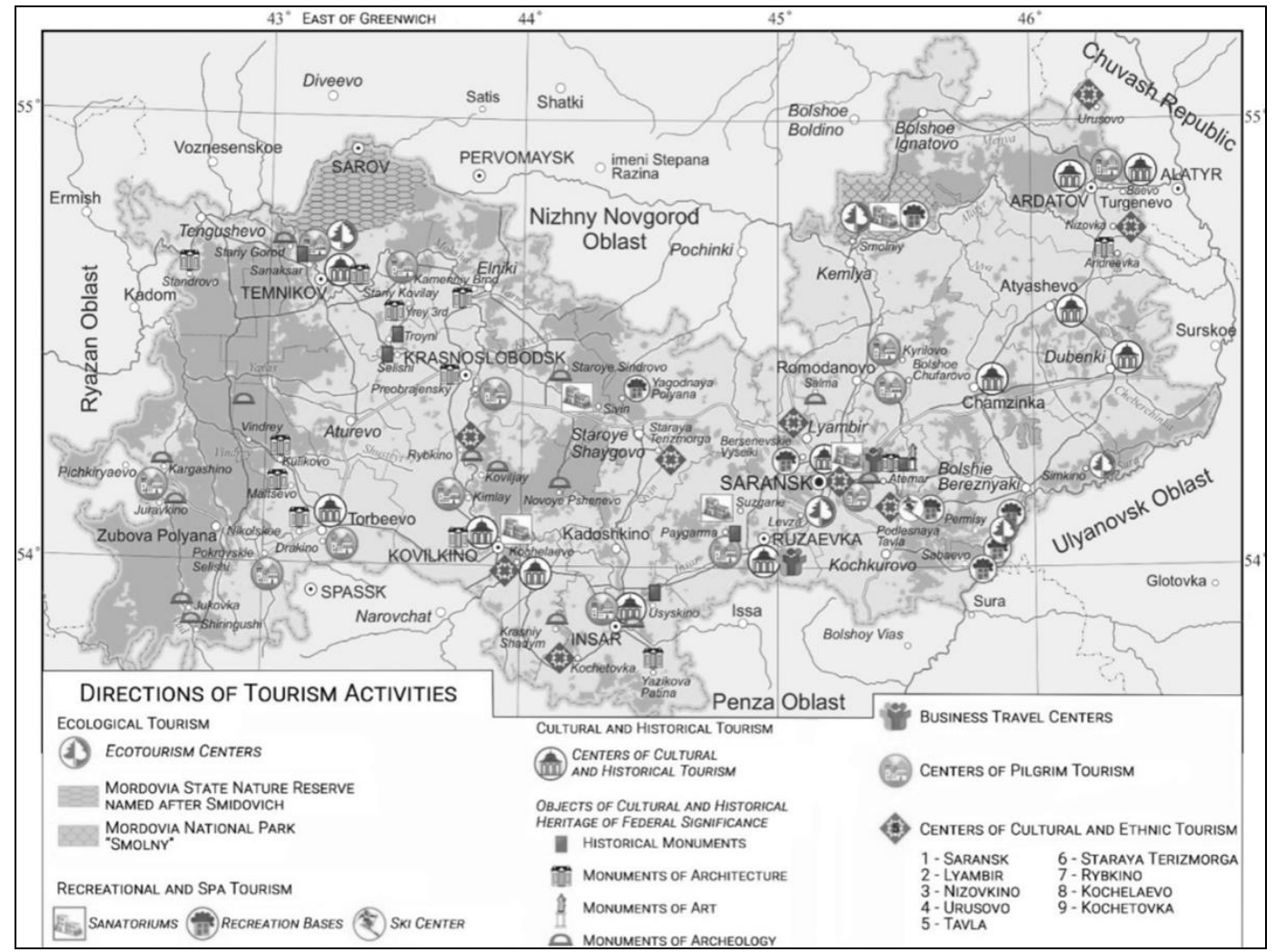

Figure 1. Sacred landscapes of Mordovia

(Source: https://tourismportal.net/social/turizm-i-rekreacia-26)

The interfaces for the map interacting are developed in JavaScript, and the manipulation of thematic layers is based on AJAX technology. In order to organize feedback with users, the function of adding comments with the ability to integrate with social networks has been used into the portal. In order to display comprehensively the multilayer structure of ethno-geographic space on the portal, it have been used the mutually complementary methods of displaying information: 1) an interactive map with various components of the regional landscape system with coordinate reference that displayed for comparative analysis; 2) an encyclopedic block that provides the user with thematic integrated textual, illustrative, cartographic information with content dynamic updating possibility. Portal interactive map allows carrying out the displaying of 
Cultural Landscapes Space-Temporal Systematization of Information

in Geoportals for the Purposes of Region Tourist and Recreational Development

thematic layers to form the space-temporal structure of the national (cultural) landscape, based on the study of relationships between natural, social and economic objects. The interactive map layers in the aggregate allow to reveal the qualitative features of the natural and cultural heritage formed during the centuries-old economic development of the landscapes as a part of the Oksko-Volzhsky interfluves.

The key elements of the interactive map are settlements. Their description reveals the multilayered cultural landscape: toponymy, settlements history, development stages and population dynamics, and ecological features of landscapes. Portal's encyclopedic block contains more than 500 illustrations in thematic sections. It provides a comprehensive space-temporal characterization the Republic of Mordovia national landscape and includes thematic blocks: "Nature", "History", "Society", "Economics", "Ecology", "Areas of Mordovia". On the portal "Natural and Cultural Heritage of Mordovia", as auxiliary functional elements, historical and modern photographs are given. Being means of forming an information model of the national landscape, it is a convenient tool for educational and scientific activities and for creating a favorable investment climate. In terms of communication, the geoportal can be integrated into tourism information systems at the national and local levels.

In this case, special attention should be paid to the creation and support of the following main functions: timely and accurate information provision on the destination; effective and continuous communication with consumers; uninterrupted opportunities provision for electronic transactions; sustainable mechanisms for customer relationships facilities. The interaction between these elements is dynamic and holistic.

The change in each of them affects the state of others and allows maintaining the balance in the system of ethno-cultural space. The successful development of the information function of geoportals based on spatial data infrastructures is helped by the evolutionary promotion of social systems to the next, most important level - the communication one. This is the level when communication takes place through the various communication channels by transforming elements of trust. Well-developed communications create the conditions for an effective dialogue, the formation of sustainable relationships and increased customer loyalty.

\section{RESULTS}

The methodological basis of the study of the natural and historical heritage in the cultural landscape is based on two obligatory aspects: chorological and chronological. The territorial approach reveals the spatial patterns of interaction between natural and historical-cultural heritage objects, their organization in the cultural landscape.

The historical approach demonstrates the temporal features of changing states of cultural landscapes (natural and historical heritage), their change under the influence of natural and socio-economic factors. Both aspects should be considered and used only in interconnection and interaction. The most important aspect of the study is regional geographic analysis. It aims to identify the features of natural and cultural heritage evolution at various historical stages within a specific territory. Methodologically, it should be based on the functional, structural and situational types of analysis.

This approach provides for multi-stage dismemberment of the region according to natural, socio-economic characteristics and features of the manifestation of the natural and historical heritage in the cultural landscape.

Cultural landscapes represent multi-level historical formations. They formed during the complex interaction of diverse natural, technical and social processes as a result of economic and information natural territorial complexes development and 
Anatoliy A. YAMASHKIN, Stanislav A. YAMASHKIN, Marina Yu. AKSYONOVA, Marija CIMBALJEVIĆ, Dunja DEMIROVIĆ, Nikola VUKSANOVIĆ, Nikola MILENTIJEVIĆ

reflect the characteristics of the local population material and spiritual culture. The change of states (evolution) of cultural landscapes implies the need to study the natural and historical heritage, cultural traditions that ensure the livelihoods of the region's population, and the features of innovative technologies implanting.

The general program for the identification of cultural landscapes should include: the first stage is landscape analysis; it allows to reflect the area natural conditions originality (variety) that determined the territory economic development features and the aesthetic qualities of landscapes; the second stage is the analysis of the existing settlement system and the degree of the territory economic development; the third stage is an analysis of the ethnographic features of the localities, manifested in the originality and special way of life of the local population; the fourth stage is a cultural analysis of historical and memorial monuments, ancient villages and estates, historical and cultural centers associated with famous scientists and artists; single monuments of civil architecture, temples, industrial architecture objects.

The most important directions for optimizing of the natural and historical heritage in cultural landscapes usage and preservation are: 1) compilation of the natural and historical heritage objects cadastre, the recreational and economic value of heritage objects determination; 2) ensuring the development of the cultural landscape with the aim of reviving folk traditions, crafts, folklore, and traditional forms of nature management; 3) identification of factors that destroy the cultural landscape; the organization of the natural and historical heritage objects monitoring, improving control over compliance with sanitary and hygienic conditions; 4) a set of measures development to ensure the landscapes attractiveness conservation and the image of natural and historical heritage in cultural landscapes promotion; 5) the creation of infrastructure (guest houses, mini-hotels, service firms); conducting investment campaigns to attract funds for the restoration, conservation, restoration of heritage sites.

Analysis and visualization of ethno-geographical space is carried out on the tourist portal in order to increase the recreational potential implementation. Information on developed forms of tourism, as well as established destinations at the national level, is supplemented by interactive maps. They illustrate the territorial importance of tourism and its main forms, form a picture of cultural landscapes with a high degree of recreational and tourist potential. The portal forms a model of the cultural national landscape that provides coordination of the search and rational use of data on ethno-geographical space. To effectively display the multilayer structure of ethno-geographical space on the portal, mutually complementary methods of displaying information are used: an interactive map and an encyclopedic block.

\section{Acknowledgment}

The reported study was funded by RFBR according to the research project № 2037-70055.

\section{REFERENCES}

Brown, S. (2012). Applying a cultural landscape approach in park management: an Australian scheme. Parks, 18(1), 99.

Gkonos, C., Iosifescu Enescu, I., \& Hurni, L. (2018). Spinning the wheel of design: evaluating geoportal Graphical User Interface adaptations in terms of human-centred design. International Journal of Cartography, p. 1-21.

Goeldner, C. R., \& Ritchie, J. R. B. (2009). Tourism: principles, practices, philosophies. John Wiley \& Sons, Inc., New Jersey. 
Gordon, J. E. (2018). Geoheritage, geotourism and the cultural landscape: Enhancing the visitor experience and promoting geoconservation. Geosciences, 8(4), 136.

Katsoni, V. (2015). Application of a Cultural Landscape Tourism Marketing Management Approach in a Mountainous Area. In Cultural Tourism in a Digital Era (pp. 121-130). Springer, Cham.

Koszewski, K., Kowalski,P., Olszewski R., \& Włochyński L. (2018). Map Portal as a Tool to Share Information on Cultural Heritage Illustrated by the National Heritage Board Geoportal. In Advances in Digital Cultural Heritage: International Workshop, Funchal, Madeira, Portugal, 28.o6.2017, Revised Selected Papers, Vol. 10754, p. 48-64.

Leiper, N. (1979). The framework of tourism: towards a definition of tourism, tourist, and the tourist Industry. Annals of Tourism Research, vol.6, no. 4, p. 390-407.

Nikolaev, V. A. (2000). Cultural landscape - geoecological system. Bulletin of Moscow University. Series 5: Geography, no. 6, p. 3-9.

Okladnikova, E. A. (2014). Sacred landscape: theory and empirical research. Direkt-Media, Berlin.

Schulp, C. J., Levers, C., Kuemmerle, T., Tieskens, K. F., \& Verburg, P. H. (2019). Mapping and modelling past and future land use change in Europe's cultural landscapes. Land Use Policy, 8o, 332-344.

Smith, J. (2014). 11 Applying a Cultural Landscape Approach to the Urban Context. Conserving Cultural Landscapes: Challenges and New Directions, 7, 182.

Swetnam, R. D., Harrison-Curran, S. K., \& Smith, G. R. (2017). Quantifying visual landscape quality in rural Wales: A GIS-enabled method for extensive monitoring of a valued cultural ecosystem service. Ecosystem Services, 26, 451-464.

Taylor, K. (2008). Landscape and Memory: cultural landscapes, intangible values and some thoughts on Asia. 16th ICOMOS General Assembly and International Symposium: "Finding the spirit of place - between the tangible and the intangible", 29 sept - 4 oct 2008, Quebec, Canada.

Taylor, K., \& Lennon, J. (2012). Prospects and challenges for cultural landscape management. In Managing cultural landscapes. Routledge, Taylor \& Francis Group.

Tieskens, K. F., Van Zanten, B. T., Schulp, C. J., \& Verburg, P. H. (2018). Aesthetic appreciation of the cultural landscape through social media: An analysis of revealed preference in the Dutch river landscape. Landscape and Urban Planning, 177, 128-137.

Van Der Valk, A. (2014). Preservation and development: The cultural landscape and heritage paradox in the Netherlands. Landscape Research, 39(2), 158-173.

Vîlceanu, C. B., Grecea, C., \& Herban, S. (2017). Spatial data geoportal for Local Administration-smart solution for a secure and valuable cultural heritage. Revista de Geodezie, Cartografie şi Cadastru Journal of Geodesy, Cartography and Cadastre, 12.

Wang, Y., \& Fesenmaier, D. (2007). Collaborative destination marketing: a case study of Elkhart County Indiana. Tourism management, vol.28, no. 3, p. 863-875.

Whelan, Y. (2016). Heritage, memory and the politics of identity: New perspectives on the cultural landscape. Routledge.

Yamashkin S. A., Radovanović M. M., Yamashkin A. A., Barmin A. N., Zanozin V. V., \& Petrović M. D. (2019). Problems of Designing Geoportal Interfaces. GeoJournal of Tourism and Geosites, year XII, no. 1, vol, 24, p. 88-101, Oradea University Press, Oradea.

Yamashkin, A. A., Timashev, I. E., \& Mahaev, V. B. (2003) Cultural Landscape Mordovia (Geoecological Problems and Landscape Planning). Mordovian University Press, Saransk.

Yamashkin, S., Radovanovic, M., Yamashkin, A., \& Vukovic, D. (2018). Improving the Efficiency of the ERS Data Analysis Techniques by Taking into Account the Neighborhood Descriptors. Data, vol. 3, no. 2, p. 18.

*** Geoportal of the Natural and Cultural Heritage of Mordovia. Retrieved from: https://tourismportal.net/ [Accessed 18.11.2019]

Submitted:

31.12.2019
Revised:

30.03.2020
Accepted and published online

03.04 .2020 